\title{
UTEROVAGINAL PACKING WITH ROLLED GAUZE IN POST-PARTUM HAEMORRHAGE, A RETROSPECTIVE STUDY IN MALDA MEDICAL COLLEGE, WEST BENGAL
}

\author{
Malay Sarkar'1, Jaydeb Mandal², Dibyendu Roy33
}

${ }_{1}^{1}$ Associate Professor, Department of Obstetrics and Gynaecology, Malda Medical College and Hospital, Malda, West Bengal, India. ${ }^{2}$ Assistant Professor, Department of Obstetrics and Gynaecology, Malda Medical College and Hospital, Malda, West Bengal, India. ${ }^{3}$ RMO-Cum-Clinical Tutor, Department of Obstetrics and Gynaecology, Malda Medical College and Hospital, Malda, West Bengal, India.

\section{ABSTRACT}

\section{BACKGROUND}

Post-Partum Haemorrhage (PPH) is one of the five leading causes of maternal death in the developed and developing countries. PPH less than up to $1000 \mathrm{ml}$ is well tolerated by a healthy pregnant woman particularly due to physiological increase in the plasma and the red cell mass during pregnancy. We wanted to determine efficacy of uterovaginal packing and its sequelae in low resource settings.

\section{METHODS}

After ethical committee permission and informed patient consent, a four-year retrospective study was conducted in the department of Obstetrics and Gynaecology of Malda Medical College, West Bengal, India. Total number of vaginal deliveries was 41990 in last four years (2014-2018). Total fifty-three (n-53) cases of primary PPH following vaginal deliveries who were hemodynamically stable after initial resuscitation with crystalloid and blood but unresponsive to bimanual compression and medical therapy were managed with uterovaginal packing for 24 hours. Traumatic PPH, PPH due to retained placental tissue or PPH following caesarean deliveries were excluded.

\section{RESULTS}

Out of fifty-three (53) cases, PPH was arrested in forty-eight (48) cases only five (5) cases required further surgical therapy. Combined utero-ovarian artery ligation (quadruple ligation) was done in one patient, and two patients responded to bilateral internal iliac artery ligation (BIIL) or hypogastric artery ligation (HAL). Two patients needed peri partum hysterectomies they continued to lose blood in spite of all conservative uterus saving methods.

\section{CONCLUSIONS}

Uterovaginal packing is a convenient and effective procedure for controlling intractable PPH if detected and managed promptly, when patient is hemodynamically stable. It is very much effective procedure in low resource setting particularly in rural India. Based on our study $90 \%$ of woman responded to utero vaginal roller gauze packing. In life threatening haemorrhage uterine packing will not only halt the blood loss and preserve the uterus but also gives an opportunity to reverse and correct any consumptive coagulopathy. By using the uterine roller packing one would expect the total blood loss to be reduced and blood products are avoided. Every obstetrician must be familiar with this simple method in order to avoid having to perform a hysterectomy and preserving the reproductive capability as well as diminishing the operative morbidity and mortality. Uterovaginal packing is a useful technique for control of post-partum haemorrhage in any set up with low resource setting. It is simple, easy technique requiring less skill which can be taught easily to the trainee residents.

\section{KEY WORDS}

Bilateral Hypogastric Artery Ligation, Hysterectomy, Hemodynamic Status, PPH, Quadruple Ligation, Uterovaginal Packing, Roller Gauze

HOW TO CITE THIS ARTICLE: Sarkar M, Mandal J, Roy D. Uterovaginal packing with rolled gauze in post-partum haemorrhage, a retrospective study in Malda medical college, West Bengal. J. Evolution Med. Dent. Sci. 2019;8(27):2162-2165, DOI: 10.14260/jemds/2019/474

\section{BACKGROUND}

Primary PPH is one of the five most common causes of maternal mortality in the developed and developing countries. ${ }^{1}$

PPH less than up to $1000 \mathrm{ml}$ is well tolerated by a healthy pregnant woman particularly due to physiological increase in

'Financial or Other Competing Interest': None.

Submission 14-02-2019, Peer Review 11-04-2019,

Acceptance 17-04-2019, Published 08-07-2019.

Corresponding Author:

Dr. Dibyendu Roy,

Vill+PO+PS-Minakhan-743425,

North 24 Parganas,

West Bengal, India.

E-mail: dibyendulive@gmail.com

DOI: $10.14260 /$ jemds $/ 2019 / 474$

\section{(c) $(1) \ominus$}

the plasma and the red cell mass during pregnancy. PPH is responsible for an annual mortality of 150000 women/year. ${ }^{2}$ Leading cause of $\mathrm{PPH}$ is uterine atony in $>90 \%$ of cases. Whereas genital tract trauma, retained product of conception and coagulopathy are the other causes. PPH is an obstetric emergency which requires prompt diagnosis and effective action to prevent maternal mortality 3 . PPH occurring in first 24 hours following delivery is called primary $\mathrm{PPH}$, and PPH occurring after 24 hours but up to 12 weeks is called secondary PPH. California maternal quality care collaborative obstetric haemorrhage protocol describes the following stages of PPH.

Stage 0: Blood loss $<500 \mathrm{ml}$ in vaginal delivery and $<1000 \mathrm{ml}$ in caesarean delivery with stable vital sign.

Stage 1: Blood loss $>500 \mathrm{ml}$ with vaginal delivery or $>1000 \mathrm{ml}$ with caesarean delivery or change in vital sign $>15 \%$ or HR 
$>=110 / \mathrm{min}, \mathrm{BP}<=85 / 45,0_{2}$ saturation $95 \%$ or increased bleeding during recovery or postpartum.

Stage 2: Continued bleeding or vital sign instability and 1000$1500 \mathrm{ml}$ cumulative blood loss.

Stage 3: Cumulative blood loss $>1500 \mathrm{ml},>2$ units PRBC given vitals sign unstable or suspicion of DIC.

Recently a term the "golden hour" is applicable in the management of primary PPH. The golden hour is the time at which resuscitation must be commenced to ensure the best chance of survival. The probability of survival decreases sharply after first hour if the patient is not effectively resuscitated. ${ }^{4}$

For the general management of PPH a rule of 30 has been proposed. If the patients systemic blood pressure falls by 30 $\mathrm{mm}$ of $\mathrm{Hg}$, Heart rate rises by 30 beats/min, respiratory rate rises to 30 breaths $/ \mathrm{min}$, and haemoglobin or haematocrit drops by $30 \%$ and her urine output is $<30 \mathrm{ml} /$ hour then the patient must have lost at least $30 \%$ of her blood volume and is in moderate shock leading to severe shock. ${ }^{5}$

The use of ' shock index'(SI) may be valuable in the monitoring $o$ and general management of women with PPH. It refers to heart rate (HR) divided by systolic blood pressure (SBP). The normal value is 0.5 to 0.7 , however with significant haemorrhage it increases to 0.9 to 1.1 . The change in shock index (SI) of an individual patient appears to be a better correlate in identifying early acute blood loss than the HR, SBP, or DBP (Diastolic blood pressure) used in isolation. ${ }^{6}$

Among many other methods of controlling PPH (eg. Medical and surgical method), uterine tamponade by packing is easy and requires minimal expertise and can be done even in low resource settings.

Uterovaginal packing for PPH had been in use previously for decades but due to fear of infection and concealed haemorrhage its use subsequently declined. However isolated reports of its successful use have been published. ${ }^{7}$

Uterovaginal packing by causing mechanical compression of uterine vascular sinuses is cheap, effective and quick method of securing haemostasis in large no of cases. ${ }^{8}$

So, we decided to study the effectiveness of uterine packing as the management of PPH in low resource settings like ours and in significant number of patients.

Malda Medical College is a rural tertiary referral centre where there are large numbers of PPH cases due to high parity, grand multipara, and large number of unbooked cases. These PPH predisposing factors are due to low socio-economic status, illiteracy and poor transport in some remote areas of the district. But being located in periphery it lacks facilities and expertise needed for surgical procedures. Thus, uterovaginal packing may be an effective alternative to further surgical procedure in patients with uncontrolled PPH. Aim of our study is to assess the effectiveness of uterovaginal packing in the management of PPH and observe its outcome.

\section{Aims and Objectives}

To determine efficacy of uterovaginal packing and its sequalae in low resource settings.

\section{Place of Study}

Department of Gynaecology and Obstetrics, Malda Medical College and Hospital.

\section{METHODS}

After ethical committee permission and informed patient consent, a four-year retrospective study was conducted in the department of Obstetrics and Gynaecology of Malda Medical College, West Bengal, India. Total number of vaginal deliveries was 41990 in last four years (2014-2018). Uterovaginal packing was given in 53 cases of atonic $P P H(n=53)$. Patients with atonic $\mathrm{PPH}$, who were haemodynamically stable after initial resuscitation with crystalloid and blood transfusion but remained refractory to uterotonic drug were selected for this study. Traumatic PPH, PPH following caesarean section, secondary $\mathrm{PPH}$, hemodynamically unstable patients even after resuscitation with fluid and blood, PPH due to retained placental tissue were excluded from study. Uterus was packed using sterile gauze of approximately 3-4 meters soaked in povidone iodine solution starting from one cornua to other cornua of uterus in such a way that no empty space left behind using uterine dressing forceps. Vaginal packing was given following uterine packing to apply additional pressure to the uterine packing. Uterovaginal packing was left in situ for 24 hours. Simultaneous Oxytocin infusion was continued (15 units in $500 \mathrm{ml}$ of Normal saline at the rate of 20 drops per minute)antibiotic coverage with Ceftriaxone and sulbactam 1.5 gm intravenously (IV) twice daily after proper skin test and metronidazole $500 \mathrm{mg}$ IV thrice daily to all patients for 2 days then Tab metronidazole 400, orally thrice daily for 3 days. BP, pulse rate and height of the uterine fundus were recorded as baseline parameters just after the uterovaginal packing were applied. Foley's catheter was inserted to monitor hourly urine output. BP, pulse rate and fundal height of uterus were recorded every 30 minutes. When uterine fundal height was at the same level and patient was haemodynamically stable after 24 hours, packs were removed. Packs were removed in less than 24 hours if there was any sign of active blood loss even with pack in situ. Packs were removed first from the vagina and then from the uterus. Puerperal pyrexia was included as post packing morbidity.

\section{Statistical Analysis}

Data was analysed by SPSS version 11. Frequency and percentage were calculated for qualitative variable e.g., efficacy, age, parity and complications.

\section{RESULTS}

Uterovaginal packing were done in 53 cases and we have observed $90.56 \%$ success rate among the patients who were managed with uterovaginal packing. Out of fifty-three (53) cases, PPH was arrested in forty-eight (48) cases only five (5) cases required further surgical therapy. Combined utero ovarian artery ligation (Quadruple ligation) was done in one patient, and two patients responded to bilateral internal iliac artery ligation (BIIL) or hypogastric artery ligation (HAL).

Out of fifty-three cases, conservative method with uterovaginal packing failed to control bleeding in five patients only. Two of them needed subtotal hysterectomy, two needed bilateral hypogastric artery ligation and one needed quadruple ligation (both uterine arteries and ovarian arteries). 


\begin{tabular}{|c|c|c|}
\hline $\begin{array}{c}\text { Total Number of Patients } \\
\text { with Uterovaginal Packing }\end{array}$ & $\begin{array}{c}\text { Number of Patients Who } \\
\text { Responded to Uterovaginal } \\
\text { Packing }\end{array}$ & $\begin{array}{c}\text { Efficacy } \\
\text { Rate }\end{array}$ \\
\hline \multicolumn{2}{|c|}{} & 48 \\
\hline \multicolumn{2}{|c|}{ Table 1. Efficacy Rate of Uterovaginal Packing } \\
\hline
\end{tabular}

\begin{tabular}{|c|c|c|}
\hline Outcome & Number of Cases & Percentage \\
\hline Control of PPH with packing & 48 & $90.56 \%$ \\
\hline Bilateral utero ovarian artery ligation & 1 & $1.88 \%$ \\
\hline Bilateral hypogastric artery ligation & 2 & $3.77 \%$ \\
\hline Peripartum hysterectomy & 2 & $3.77 \%$ \\
\hline \multicolumn{2}{|c|}{ Table 2. Outcome of Uterovaginal Packing } \\
\hline
\end{tabular}

\begin{tabular}{|c|c|c|c|}
\hline $\begin{array}{c}\text { Age in } \\
\text { Years }\end{array}$ & $\begin{array}{c}\text { Number } \\
\text { of } \\
\text { Patients }\end{array}$ & $\begin{array}{c}\text { Number of Patients } \\
\text { Controlled by Packing }\end{array}$ & $\begin{array}{c}\text { Percentage of Patients Who } \\
\text { Responded to Packing }\end{array}$ \\
\hline $20-24$ & 29 & 29 & $100 \%$ \\
\hline $24-29$ & 16 & 15 & $93.75 \%$ \\
\hline $30-34$ & 6 & 5 & $83.3 \%$ \\
\hline$\geq 35$ & 3 & 1 & $33.3 \%$ \\
\hline \multicolumn{3}{|c|}{ Table 3. Relation of Age with Success of Uterovaginal Packing } \\
\hline
\end{tabular}

\begin{tabular}{|c|c|c|c|c|}
\hline Parity & $\begin{array}{c}\text { Number } \\
\text { of } \\
\text { Patients }\end{array}$ & $\begin{array}{c}\text { Number of } \\
\text { Patients Who } \\
\text { Responded to } \\
\text { Packing }\end{array}$ & $\begin{array}{c}\text { Percentage of Patients } \\
\text { Who Responded to } \\
\text { Packing }\end{array}$ & $\begin{array}{c}\text { Average Units } \\
\text { of Whole } \\
\text { Blood } \\
\text { Transfuse }\end{array}$ \\
\hline Primi & 8 & 8 & $100 \%$ & $2.25 \pm 0.62$ \\
\hline P 2 & 10 & 10 & $100 \%$ & $2.4 \pm 0.67$ \\
\hline P 3 & 29 & 28 & $96.55 \%$ & $2.68 \pm 0.72$ \\
\hline P 4 & 5 & 3 & $60 \%$ & $4.8 \pm 0.65$ \\
\hline P $\geq 5$ & 2 & 1 & $50 \%$ & $5.5 \pm 0.81$ \\
\hline \multicolumn{7}{|r|}{ Table 4. Relation of Parity with Success of Uterovaginal Packing } \\
\hline
\end{tabular}

\begin{tabular}{|c|c|c|c|}
\hline Parity & $\begin{array}{c}\text { Number of Patient } \\
\text { Who Needed } \\
\text { Bilateral } \\
\text { Hypogastric Artery } \\
\text { Ligation }\end{array}$ & $\begin{array}{c}\text { Number of Patients } \\
\text { Who Needed } \\
\text { Bilateral Utero- } \\
\text { Ovarian Artery } \\
\text { Ligation }\end{array}$ & $\begin{array}{c}\text { Number of } \\
\text { Patients Who } \\
\text { Needed } \\
\text { Peripartum } \\
\text { Hysterectomy }\end{array}$ \\
\hline 3 & 2 & 0 & 0 \\
\hline 4 & 0 & 1 & 1 \\
\hline$\geq 5$ & 0 & 0 & 1 \\
\hline \multicolumn{2}{|r|}{ Table 5. Relation of Parity with Other Invasive Procedures } \\
\hline
\end{tabular}

\begin{tabular}{|c|c|c|}
\hline $\begin{array}{c}\text { Number of Patients Who } \\
\text { Underwent Uterovaginal } \\
\text { Packing }\end{array}$ & $\begin{array}{c}\text { Number of Patients } \\
\text { Who Developed } \\
\text { Pyrexia }\end{array}$ & $\begin{array}{c}\text { Percentage of } \\
\text { Patients Who } \\
\text { Developed Pyrexia }\end{array}$ \\
\hline 53 & 3 & $5.66 \%$ \\
\hline \multicolumn{2}{|c|}{ Table 6. Incidence of Post Packing Pyrexia } \\
\hline
\end{tabular}

It was observed from our study that success rate of uterovaginal packing is inversely proportional with increase in age and parity (Table $3 \& 4$ ).

Requirement of blood transfusion was more with increase in age and parity (Table 4 and 5) respectively.

Increase in parity also has direct relation with requirement of hysterectomy (Table 5). Three patients developed fever more than $100.4^{\circ} \mathrm{F}$ (incidence 5.66\%) Table 6 and one patient developed episiotomy wound infection (incidence 1.88\%) Table 7.

\section{DISCUSSION}

PPH requires immediate resuscitations. After excluding traumatic cause and retained placental tissue, efforts are directed towards making uterus contracted by bimanual compression and uterotonic drugs. If these are not successful, one has to resort for stepwise surgical devascularisation. Surgical methods to control PPH are many. An outline of stepwise uterine revascularization procedure are-

1. B Lynch compression suture and multiple square suture.

2. Ligation of uterine arteries.

3. Ligation of ovarian arteries.

4. Ligation of anterior decision of internal iliac artery.
5. Angiography selective arterial embolisation which can be done using gel foam under radiographic guidance by interventional radiologist.

Last resort to control post-partum haemorrhage is peripartum hysterectomy (Total or subtotal).

Before resorting to surgical procedures, an alternative option is uterovaginal packing, which is easy and quick to perform.

Wittich et al, have recommended uterine packing as pre surgical procedure after exclusion of laceration of lower genital tract and retained placental tissue. ${ }^{9}$ Our study also included non-traumatic and non-placental uterine haemorrhage with success rate of uterine packing $90.56 \%$.

In a study by Ali et al, forty-two patients in whom uterovaginal packing was given, thirty-six (86\%) responded to the procedure, failure to achieve haemostasis occurred in 6 cases $(14 \%)$, peri partum hysterectomy was done in three cases $(7 \%)$. While one (2\%) patient died due to multiple organs failure. ${ }^{10}$ This study is similar to our study.

Our success rate is also similar to study conducted by Haq G et al. ${ }^{11}$

Incidence of caesarean hysterectomy was more in patients with parity four or more (TABLE 5). This is similar to the observations made by Ozoden et al (2005).12

In a previous study by Nwagha et al, 2005 pack was removed after 24 hours, Haq et al, 2005 removed uterine packing after 12 to 24 hours depending on the case and Maier et al, 1993 have reported earliest removal of pack at 5 hours and late after 96 hours.11,13,14 We had kept uterovaginal pack for 24 hours if there was no hemodynamic instability or increase in fundal height of uterus, so that PPH is properly controlled and chances of infection is minimized.

Average blood loss in our study is comparable to previous study. ${ }^{12,13}$ We observed in our study that requirement of blood transfusion has increased with increase in age and parity Table 4 and 5. This is probably due to presence of pre-existing anaemia and less contractile uterine muscular tissue in multi parous women as mentioned in Dutta D C 2004. ${ }^{15}$

A study conducted by Roman et al, showed that there was minimal fever which settles with medicine and was of no clinical significance, 16 Comparing this with our study in respect to post insertion morbidity, 3 patients developed fever (5.66\%) which settled down with paracetamol and antibiotics.

In 48 cases PPH was completely controlled and only in 5 cases PPH continued. Two of them needed subtotal hysterectomy, two needed bilateral hypogastric artery ligation and one needed bilateral utero-ovarian artery ligation.

In our study, it was observed that success rate of uterovaginal packing was more in younger patients and more blood transfusion was needed in elderly patients.

It was observed in Table 4 that success rate of uterovaginal packing was decreased with increase in parity and requirement of blood transfusion was more in multi parous patients.

\section{CONCLUSIONS}

Based on our study $90 \%$ of woman responded to utero vaginal roller gauze packing. In life threatening haemorrhage uterine packing will not only halt the blood loss and preserve the uterus but also gives an opportunity to reverse and correct any consumptive coagulopathy. By using the uterine roller packing 
one would expect the total blood loss to be reduced and blood products are avoided. Every obstetrician must be familiar with this simple method in order to avoid having to perform a hysterectomy and preserving the reproductive capability as well as diminishing the operative morbidity and mortality. Uterovaginal packing is a useful technique for control of postpartum haemorrhage in any set up with low resource setting. It is simple, easy technique requiring less skill which can be taught easily to the trainee residents.

\section{REFERENCES}

[1] Mousa HA, Walkinshaw S. Major postpartum haemorrhage. Curr Opin Obstet Gynaecol 2001;13(6):595-603.

[2] Pritchard JA, MacDonald PC, Gant NF. Williams Obstetrics. Crofts Abnormalities of $3^{\text {rd }}$ stage of labour. 17th edn. New York: Appleton-Century Company 1985: p. 707-18.

[3] Penny G, Khernaghan D, Adamson L. Scottish programme for clinical effectiveness in reproductive health. Scottish confidential audit of severe maternal morbidity. Third annual report. Edinburg, 2005.

[4] Lalonde A, Daviss BA, Acosta A, et al. Postpartum hemorrhage today: ICM/FIGO initiative 2004-2006. Int J Gynaecol Obstet 2006;94(3):243-53.

[5] Chandraharan E, Arulkumaran S. Massive postpartum haemorrhage and management of coagulopathy. Obstet Gynaecol Reprod Med 2007;17(4):119-22.

[6] Birkhan RH, Gaeta TJ, Terry D, et al. Shock index in diagnosing early acute hypovolumia. Am J Emerg Med 2005;23(3):323-6.

[7] Doumouchtsis SK, Papageorghion AT, Arulkumaran S. Systemic review of conservative management of postpartum haemorrhage: what to do when medical management fails. Obstet Gynaecol Surv 2007;62(8):540-7.
[8] ACOG practice bulletin. Clinical management guidelines for obstetrician-gynecologists, No. 76, October 2006. Postpartum haemorrhage. Int J Obstet \& Gynaecol 2006;108:1039-47.

[9] Wittich AC, Salminen ER, Hazdin EL, et al. Uterine packing in combined management of obstetrical haemorrhage. Mill Med 1996;161(3):180-2.

[10] Ali T, Ghazi A, Siddiq NM. Uterovaginal packing in massive postpartum haemorrhage - a reappraisal. Pak J Surg 2008;24(1):57-9.

[11] Haq G, Tayyab S. Control of postpartum and post abortal haemorrhage with uterine packing. J Pakistan Med Association 2005;55(9):369-71.

[12] Ozaden S, Yijdirim G, Basaram T, et al. Analysis of 59 cases of emergent peripartum hysterectomies during a 13 year period. Arch Gynaecol Obstet 2005;271(4):363-7.

[13] Nwagha UI, Okaro JM, Nwagha TU. Intraoperative uterine packing with mops: an effective but underutilized method of controlling postpartum haemorrhage - experience from South Eastern Nigeria. Niger J Med 2005;14(3):279-82.

[14] Maier RC. Control of postpartum haemorrhage with uterine packing. Am J Obstet Gynaecol 1993;169(2 Pt 1):317-23.

[15] Dutta DC. Grand multipara. In: Dutta DC, edr. Textbook of Obstetrics. India: New Central Book Agency (P) Ltd., 2004;22:342-3.

[16] Roman AS, Rebarber A. Seven ways to control postpartum haemorrhage. contemporary OB/GYN Newsline 2003;3:11-14. 